\title{
Long-Term Structural Remodeling in Aplysia Sensory Neurons Requires de novo Protein Synthesis during a Critical Time Period
}

\author{
Fidelma A. O'Leary, John H. Byrne, and Leonard J. Cleary \\ Department of Neurobiology and Anatomy, University of Texas Medical School, Houston, Texas 77225
}

Long-term sensitization training induces persistent changes in both electrophysiological properties and specific structural features of sensory neurons in Aplysia californica. Previously, we found that transient elevation of intracellular CAMP could also modify these features in sensory neurons located in the pleural ganglion. In the present study we examined the role of protein synthesis in structural remodeling induced by CAMP. When applied during the intracellular injection of cAMP, anisomycin blocked increases in both the number of varicosities and the number of branch points in single sensory neurons. Exposure to anisomycin during different time periods, from as early as $12 \mathrm{hr}$ prior to cAMP injection to periods as late as $15 \mathrm{hr}$ after, indicated that the requirement for protein synthesis starts at the time of CAMP injection and extends for at least seven hours afterwards. Because it is metabolized rapidly, CAMP probably triggers a cascade of protein synthesis whose products continue to be synthesized for several hours after cAMP levels have returned to baseline. Thus, the present results suggest that the induction of long-term structural changes in sensory neurons has an extended but finite requirement for protein synthesis.

[Key words: morphology, cAMP, protein synthesis, learning, memory, Aplysia]

Central to the study of learning and memory is an understanding of the cellular mechanisms by which learning is acquired and memory is retained. Two complementary classes of mechanisms have been examined for their contribution to behavioral plasticity. These include biophysical mechanisms and structural mechanisms (for reviews see Bailey and Kandel, 1993; Byrne, 1987; Greenough and Bailey, 1988). Both classes could contribute to the modulation of pre-existing synapses, as well as to the formation of functionally new connections. The marine mollusc Aplysia californica has proven to be a useful model system in which to study the cellular mechanisms underlying several forms of learning (Castellucci et al., 1986; Byrne, 1987; Kandel and Schwartz, 1982; Byrne et al., 1993). In this animal, different forms of learning have different durations, from relatively short

\footnotetext{
Received May 9, 1994; revised Nov. 14, 1994; accepted Nov. 22, 1994.

This research was supported by National Research Service Award F3! MH09956 to F.A.O'L., NIMH Award K05 MH00649 and NIH Grant R01 NS 19895 to J.H.B., THECB Grant 1945 and NSF Grant IBN-9320549 to L.J.C., and a Biontedical Research Support Grant to the University of Texas Houston Health Science Center.

Correspondence should be addressed to Leonard J. Cleary, Department of Neurobiology and Anatomy, University of Texas Medical School, P.O. Box 20708 , Houston, TX 77225.

Copyright 1995 Society for Neuroscience $0270-6474 / 95 / 153519-07 \$ 05.00 / 0$
}

(on the order of minutes) to relatively long (on the order of days). One of these forms, long-term sensitization, has been correlated with changes in both biophysical and structural properties of neurons. Specifically, long-term sensitization training induces structural remodeling of the sensory neurons in the abdominal ganglion that mediate the gill-siphon withdrawal reflex (Bailey and Chen, 1988a). Morphological characteristics of both the axonal arbor (Bailey and Chen, 1988a; Bailey and Chen, 1988b) and synaptic terminals (Bailey and Chen, 1983) are modified.

The cellular correlates of long-term sensitization appear to be mediated by the second messenger cAMP. For example, in pleural sensory neurons, which mediate the tail-siphon withdrawal reflex (Walters et al., 1983a), intracellular injection of cAMP was sufficient to mimic the change in sensory neuron membrane currents induced by long-term sensitization training (Scholz and Byrne, 1987; Scholz and Byrne, 1988). Moreover, a similar experimental protocol resulted in modification of the axonal structure of these neurons (Nazif et al., 1991). The axonal features modified by cAMP were the same as those of siphon sensory neurons that were modified by long-term sensitization (Bailey and Chen, 1988a). Thus, cAMP can trigger the cellular mechanisms contributing to neuronal remodeling.

We attempted to further dissect these mechanisms by examining the neuron's requirement for protein synthesis both during cAMP injection and at different times prior to and following injection. Since the elevation of cyclic nucleotide is transient (Bernier et al., 1982; Bacskai et al., 1993), it is likely that it serves to initiate a more enduring process, such as protein synthesis (Goelet et al., 1986; Montarolo et al., 1986). We report here that anisomycin, an inhibitor of protein synthesis (Grollman, 1967; Jacklet, 1980), blocked the long-term structural remodeling induced by cAMP when applied during the injection of the cyclic nucleotide and also when applied from 4 to $7 \mathrm{hr}$ afterwards. Anisomycin was not effective, however, when applied 12-15 hr after cAMP injection. Thus, the induction of neuronal remodeling by CAMP has an extended but finite requirement for protein synthesis. In addition, our data support the idea that sensitizing stimuli induce a cascade of protein synthesis in the sensory neurons (Barzilai et al., 1989; Noel et al., 1993). Proteins synthesized soon after cAMP elevation may affect gene expression at later times. The protein products of these cascades of synthesis are presumably used to effect successive cellular changes, including structural remodeling, which may underlie the altered behavioral response of the animal.

\section{Materials and Methods}

Preparation of ganglia. Experiments were performed on Aplysia californica $(150-300 \mathrm{gm})$ supplied by Alacrity Marine Biological (Redondo 
Beach, CA), Marine Specimens (Pacific Palisades, CA), and Marinus Biomarine (Westchester, CA). The animals were housed in aquaria containing artificial seawater (Instant Ocean, Aquatic Systems, Mentor, OH) at $15^{\circ} \mathrm{C}$. Each animal was anesthetized by an intracoelomic injection of $\mathrm{MgCl}_{2}$ and the paired pleural-pedal ganglia were removed to separate Sylgard-lined petri dishes containing equal parts $\mathrm{MgCl}_{2}$ and artificial seawater, a dissection medium that blocks synaptic transmission during pinning and desheathing. After desheathing the pleural ganglia to expose the tail sensory neurons, the ganglia were bathed in isotonic culture medium (L-15, Sigma, St. Louis, MO; Buonomano and Byrne, 1990) for at least $30 \mathrm{~min}$.

Intracellular injection of $C A M P$ and HRP. Sensory neurons in each ganglion were selected based on their location in the medial region of the pleural sensory cluster, which innervates the tail (Walters et al., 1983a). One or two sensory neurons in each cluster were impaled with a microelectrode containing an aqueous solution of fast green dye (6 $\mathrm{mM})$ and cAMP (200 mM). The nucleotides were injected by iontophoresis, using $10 \mathrm{nA}$ hyperpolarizing pulses (Nazif et al., 1991). The experimenter performing intracellular injections did not know whether the preparation had been treated with anisomycin or its inactive derivative deacetylanisomycin.

The tissue was then incubated overnight at $15^{\circ} \mathrm{C}$. Approximately 22 hr after iontophoresis the nucleotide-filled cells were identified by their green color and with the aid of a sketch generated at the time of cAMP injection and reimpaled with double-barreled electrodes for pressure injection (Eisenstadt et al., 1973). One barrel of the electrode was filled with potassium acetate $(3 \mathrm{M})$, the other with a solution of $4 \%$ horseradish peroxidase (HRP, 4\%; Sigma) and fast green (6 mM). The HRP solution was pressure injected into the neurons by 300 msec pressure pulses. Typically, 10 pulses of 15-20 PSI were administered, and the same electrode was used for both ganglia from a single animal if possible. The HRP was allowed $2 \mathrm{hr}$ at room temperature to diffuse within the neuron, filling the proximal axon in the pleural-pedal connective and the fine branches within the neuropil of the pleural ganglion.

Histochemistry. Two hours aller HRP injection the tissue was fixed and processed as described previously (Nazif et al., 1991). The tissue was first fixed for $30 \mathrm{~min}$ in a solution of $2 \%$ glutaraldehyde in phosphate buffered saline (PBS, $0.06 \mathrm{M}$ sodium phosphate and $0.15 \mathrm{M}$ sodium chloride) containing $30 \%$ weight/volume sucrose. After rinsing for $30 \mathrm{~min}$ in PBS, the ganglia were then desheathed completely before reaction with $0.012 \%$ hydrogen peroxide in a solution of $0.025 \%$ diaminobenzidine (DAB) and $0.02 \%$ nickel ammonium sulfate in $0.1 \mathrm{M}$ imidazole to reveal the distribution of HRP. The ganglia were then dehydrated in increasing concentrations of ethyl alcohol $(\mathrm{EtOH})$, and dehydrated overnight in $100 \%$ EtOH. The tissue was then cleared for 30 min in xylenes and mounted on glass slides in Permount (Fischer, NJ). Sensory neurons were analyzed if they were sufficiently well filled to reveal branches in the pleural ganglion and if their primary axons were filled through the connective to the pedal ganglion. In addition, sensory neurons must not have been damaged during the initial desheathing or the subsequent incubation. Ganglia containing a neuron that did not meet these criteria were excluded from the experiment.

Morphology of labeled neurons was analyzed using high resolution light microscopy (Nazif et al., 1991). Analyses were performed with a blind procedure in which individual ganglia were randomly coded before scoring. When two sensory neurons were injected with HRP in a single ganglion, the total numbers of varicosities and branch points were divided by two in order to obtain the average per neuron for that ganglion. Significance was assessed with the two-tailed paired $t$ test. A $p$ value of less than 0.05 was considered significant.

\section{Results}

Intracellular injection of cAMP by iontophoresis is an effective technique for inducing long-term changes in both membrane currents and neuronal structure (Scholz and Byrne, 1988; Nazif et al., 1991). In previous experiments, neurons injected with cAMP were compared with contralateral controls injected with 5 -AMP. The two features examined were the number of varicosities and the number of branch points per neuron. Varicosities are dilations of variable size on the neuronal processes, many of which contain morphological features associated with sites of transmitter release (Bailey et al., 1979). Varicosities occur along branches, at iranch points and at the ends of branches (Fig. 1).
Branch points are sites of divergence where a neurite divides into two or more processes.

The dependence of long-term structural modifications on de novo protein synthesis was investigated by incubating ganglia in anisomycin or its inactive derivative deacetylanisomycin. Anisomycin was chosen for this study because it has been shown to block $90-95 \%$ of protein synthesis in Aplysia CNS tissue, including, specifically, the pleural ganglion (Schwartz et al., 1971; Jacklet, 1980). In addition, its effects are reversible (Grollman, 1967; Montarolo et al., 1986). In a control experiment, ganglia were bathed in anisomycin for $3 \mathrm{hr}$ without nucleotide injection and labeled with HRP $20 \mathrm{hr}$ after anisomycin washout. Under these conditions, anisomycin had no effect on sensory neuron structure (Fig. 2). There was no significant difference in the number of varicosities between sensory neurons from anisomycin-treated ganglia compared with those from contralateral control ganglia treated with the inactive derivative deacetylanisomycin ( $23 \pm 11$ vs $24 \pm 12$; mean \pm SEM; two-tailed paired $t$ test, $\left.t_{8}=0.64, n=9\right)$. Similarly this exposure to anisomycin had no significant effect on the number of branch points (13 \pm 3 vs $14 \pm 3, t_{8}=0.53, n=9$ ).

In the remaining experiments, tissue was exposed to anisomycin or deacetylanisomycin for a period of 3 hr at four different time periods relative to the time of cAMP injection (Fig. 3). In all cases anisomycin was added to one preparation (final concentration $10 \mu \mathrm{M}$ ), while deacetylanisomycin (final concentration $10 \mu \mathrm{M}$ ) was added to the contralateral control.

Exposure to anisomycin for a $3 \mathrm{hr}$ period starting $12 \mathrm{hr}$ before cAMP injection did not block structural remodeling. This time period was chosen because it ensured that cAMP would be injected at a time point when total levels of protein synthesis had returned to normal following anisomycin washout (Montarolo et al., 1986). Twenty-four hours after cAMP injection, anisomycin appeared to affect neither the number of varicosities (I, Fig. 4A) nor the number of branch points (I, Fig. $4 B$ ). There was no significant difference in varicosity number between cells exposed to anisomycin and those exposed to deacetylanisomycin ( $49 \pm 8$ vs $48 \pm 11, t_{5}=0.34, n=6$ ). Similarly, there was no significant difference in branch point number between cells exposed to anisomycin and those exposed to deacetylanisomycin $\left(21 \pm 2\right.$ vs $\left.19 \pm 3, t_{5}=0.37, n=6\right)$.

Application of anisomycin during behavioral training or its in vitro analog blocked long-term sensitization itself (Castellucci et al., 1989) and long-term synaptic facilitation (Montarolo et al., 1986). Morphological changes induced by 5-HT in cultured neurons were also blocked by anisomycin (Bailey et al., 1992b). In the present study, application of anisonicin during a similar time period, that is, during and immediately following cAMP injection, blocked increases in both the number of varicosities (II, Fig. $4 A$ ) and the number of branch points (II, Fig. $4 B$ ) in the sensory neurons. cAMP-filled cells exposed to deacetylanisomycin had about twice the number of varicosities as cAMPfilled cells exposed to anisomycin during the injection (56 \pm 8 vs $28 \pm 5)$. These values were significantly different $\left(t_{9}=3.27\right.$, $p<0.001, n=10$ ). Moreover, the number of varicosities in cAMP-filled cells exposed to deacetylanisomycin is comparable to the number of varicosities in cAMP-filled cells bathed in culture medium alone (Nazif et al., 1991). Similarly, sensory neurons exposed to deacetylanisomycin during cAMP injection had about $50 \%$ more branch points than neurons exposed to anisomycin ( $14 \pm 2$ vs $9 \pm 1)$. Again, these values were significantly different $\left(t_{9}=2.39, p<0.005, n=10\right)$. 


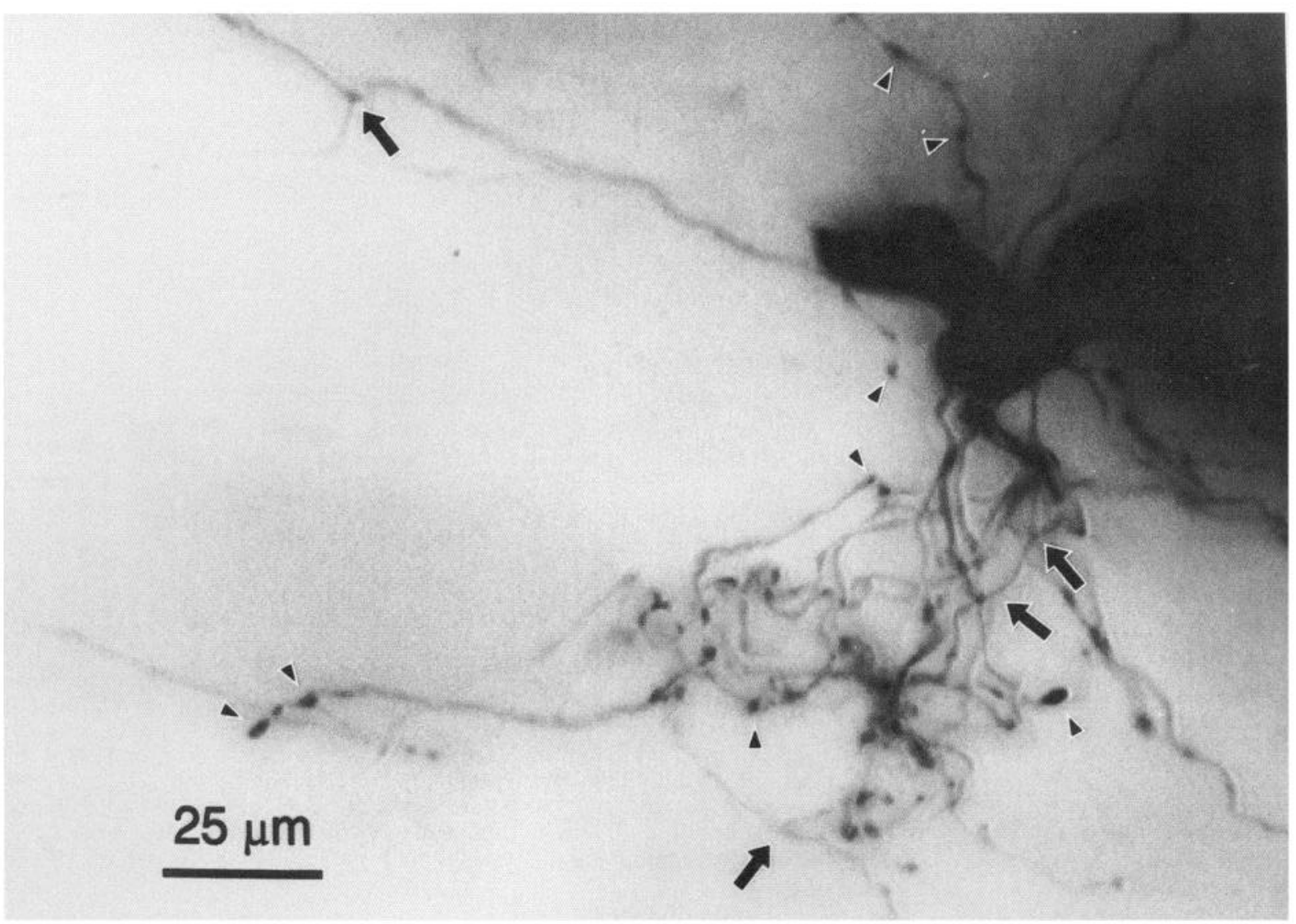

Figure 1. Morphology of pleural sensory neurons. A single sensory neuron in the pleural ganglion was labeled with HRP and examined as a whole mount. This digital composite through the neuropil of the pleural ganglion was constructed from video images of a single microscopic field at eight different focal planes. Consequently, only a portion of the arborization is represented. Numerous varicosities are apparent within this region (arrowheads). There are also several sites at which the neurites bifurcate (arrows). In the microscope, these are readily distinguished from sites where neurites cross at different depths within the tissue.

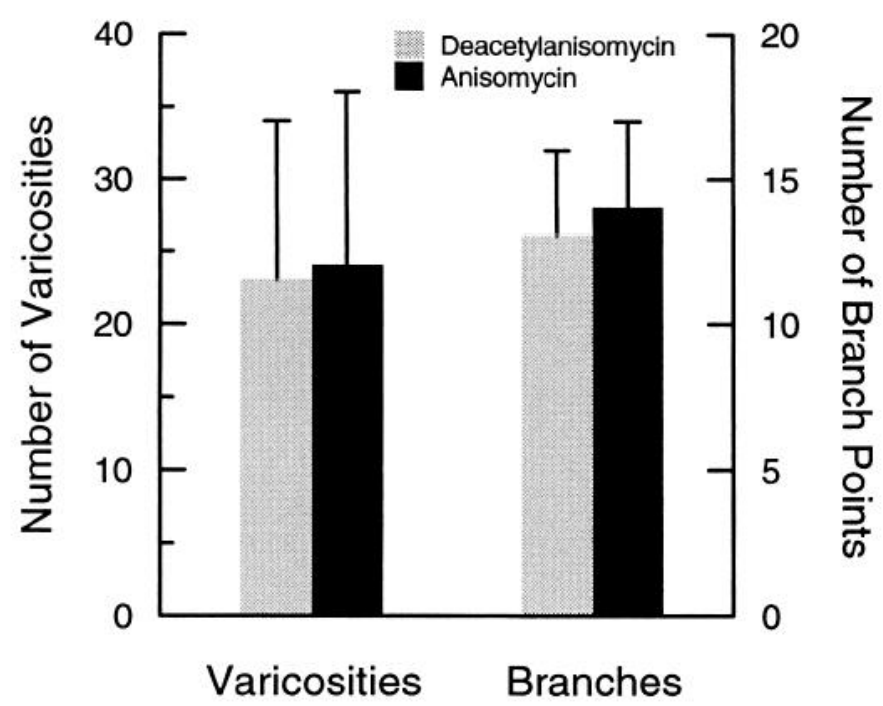

Figure 2. Effect of anisomycin on sensory neuron structure. Tissue was bathed in culture medium containing anisomycin for a period of 3 $\mathrm{hr}$ and then incubated for another $20 \mathrm{hr}$ before injection of HRP. Contralateral control ganglia were exposed to deacetylanisomycin, an inactive derivative of anisomycin. There was no difference in the number of varicosities or the number of branches between the two groups. Note that cAMP was not injected into these neurons.
An important feature of the long-term facilitation induced by 5-HT is its insensitivity to inhibitors of RNA and protein synthesis when their application is delayed by as little as $0.5 \mathrm{hr}$ following treatment (Montarolo et al., 1986). If the same mechanism supports long-term modifications of neuronal structure, then delayed application of anisomycin should be ineffective

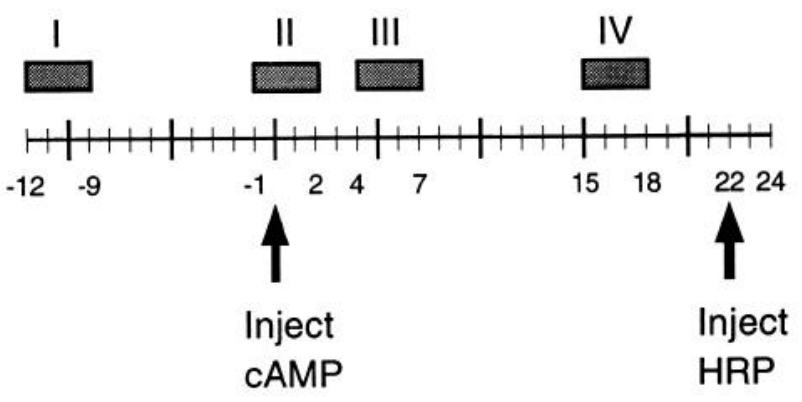

Figure 3. Time line illustrating experimental protocols. The effects of anisomycin were examined at four different periods with respect to iontophoresis of cAMP: $I, 12-9 \mathrm{hr}$ before injection; $I I, 1 \mathrm{hr}$ before to $2 \mathrm{hr}$ after injection; III, 4-7 hr after; IV, 15-18 hr after. HRP was injected at $22 \mathrm{hr}$ after cAMP injection, and the preparation was fixed 2 hr later. In all experiments, the contralateral control ganglion was exposed to deacetylanisomycin. 
A

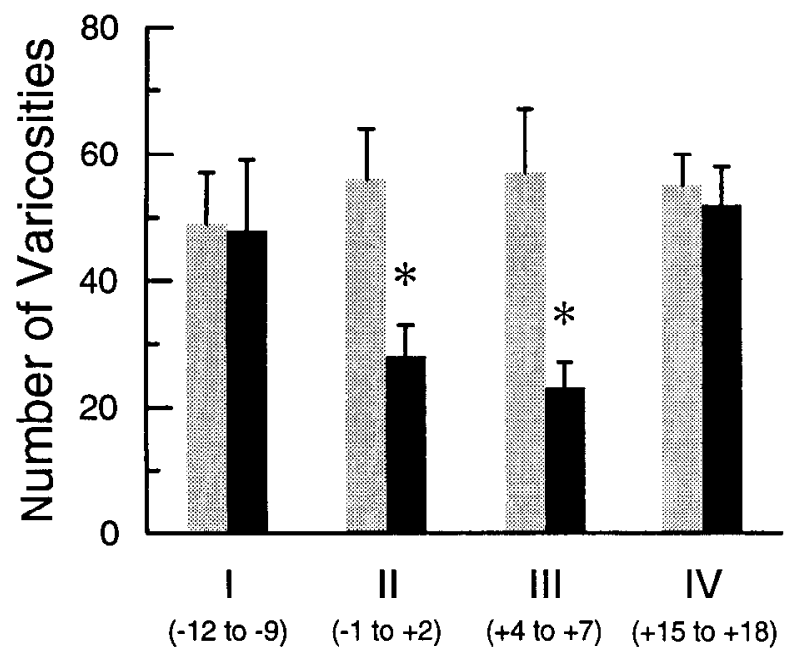

B

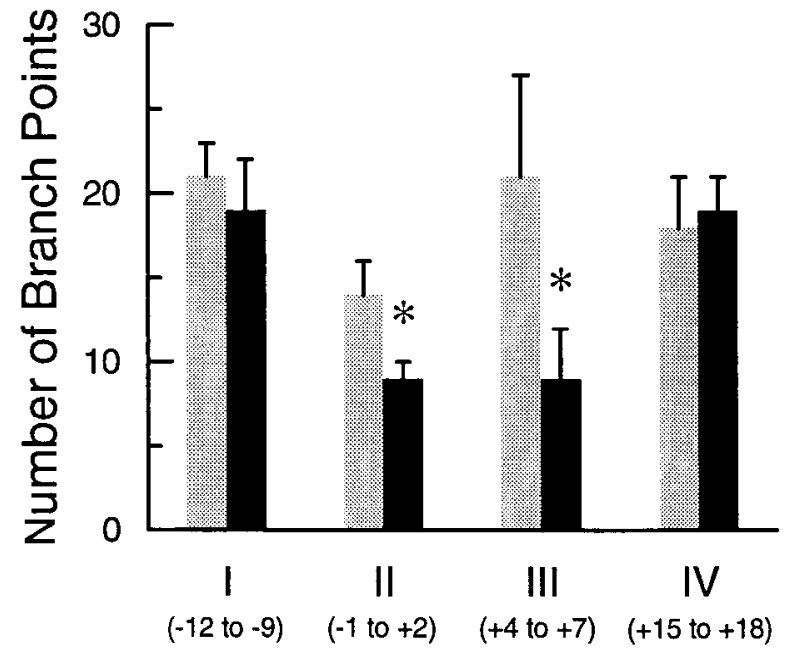

Figure 4. Effect of anisomycin on the number of sensory neuron varicosities and the number of branch points. A, Anisomycin blocked the increased number of varicosities produced by cAMP at two time periods: during cAMP injection $(I I)$ and several hours after $(I I I)$. At these times periods the number of varicosities was significantly less in anisomycin-treated neurons compared to contralateral controls treated with deacetylanisomycin $\left({ }^{*}, p<0.05\right.$, two-tailed paired $t$ test). The average number of varicosities in anisomycin-treated neurons was comparable to that in neurons that were not injected with cAMP (Fig. 2). B. Anisomycin blocked the increased number of branch points produced by cAMP at the same two time periods: during $\mathrm{c} \Lambda \mathrm{MP}$ injection $(I I)$ and several hours after $(I I I)$. $\Lambda \mathrm{t}$ these times periods the number of branch points was significantly less in anisomycin-treated neurons compared to contralateral controls treated with deacetylanisomycin $(*, p<0.05$, two-tailed paired $t$ test $)$. The average number of branch points in anisomycin-treated neurons was comparable to that in neurons that were not injected with cAMP (Fig. 2).

also. Surprisingly, application of anisomycin delayed by $4 \mathrm{hr}$ was effective in blocking the cAMP-induced structural changes, as compared with controls exposed to deacetylanisomycin (III, Fig. 4A,B). Those cells exposed to deacetylanisomycin had about twice the number of varicosities as cAMP-injected cells exposed to anisomycin ( $57 \pm 10$ vs $23 \pm 4)$. This difference was statistically significant $\left(t_{8}=5.51, p<0.001, n=9\right)$. Similarly, there was a significant difference in branch point number between cells exposed to deacetylanisomycin and those exposed to anisomycin $(21 \pm 6$ vs $9 \pm 3)$. This difference was statistically significant $\left(t_{8}=3.18, p<0.009, n=9\right)$.

In order to examine the extent of the time period during which protein synthesis was required for structural remodeling, application of anisomycin was delayed until $15 \mathrm{hr}$ after cAMP injection. Analysis of the tissue revealed that exposure to anisomycin during this time window was not effective in blocking the cAMP induced morphological changes (IV, Fig. 4A,B). There was no significant difference in varicosity number between cells receiving anisomycin or deacetylanisomycin treatment $(55 \pm 5$ vs 52 $\pm 6, t_{5}=0.34, n=6$ ). Similarly, there was no significant difference in branch point number between cells exposed to anisomycin or those exposed to deacetylanisomycin $(18 \pm 3$ vs $19 \pm 2, t_{5}=0.29, n=6$ ). Thus, by $15 \mathrm{hr}$ after cAMP injection, the induction of the morphological changes is no longer sensitive to anisomycin exposure. Presumably by this time the new proteins required for the structural remodeling have already been synthesized.

\section{Discussion}

Our earlier findings indicated that a transient elevation in the level of the intracellular second messenger cAMP was sufficient to trigger structural remodeling in the tail sensory neurons (Nazif et al., 1991). The results reported here indicate that these effects are mediated by cellular mechanisms requiring de novo protein synthesis, and presumably modulation of gene expression, during and following the period of cAMP application. Similar results were obtained in cultured neuron preparations using 5-HT to elevate intracellular cAMP and induce long-term synaptic facilitation (Bailey et al., 1992b). Our experiments were conducted with intact ganglia and, in addition, go several steps further by examining directly the role of cAMP and the time periods during which the morphological effects of cAMP are sensitive to anisomycin. We found that when application of anisomycin was delayed by $4 \mathrm{hr}$, but not $15 \mathrm{hr}$, structural remodeling was blocked. These results suggest that structural remodeling is due in part to a cascade of intracellular events with a relatively long time course that is initiated by a transient elevation of cAMP concentration.

\section{Role of protein synthesis in the induction of structural remodeling}

The cellular mechanisms that regulate varicosity formation and neurite outgrowth in Aplysia are not known. Therefore, it is difficult to identify the specific step that is disrupted by inhibitors of protein synthesis. Nevertheless, a detailed model has been developed describing a cellular pathway by which gene expression is altered by cAMP (Byrne et al., 1993; Kennedy et al., 1992a). The first step in this model is liberation of the catalytic subunit of protein kinase $\mathrm{A}$, which has been shown to migrate to the cell nucleus (Bacskai et al., 1993). In the nucleus, phosphorylation of the cAMP responsive element binding protein (CREB) would lead to increased expression of proteins whose synthesis is regulated by the CRE gene sequence (Dash et al., 1990; Kaang et al., 1993). The ability of protein synthesis in- 
hibitors to block the effects of elevated cAMP is presumably due to the fact that the newly expressed mRNA must be translated into a protein before it can be effective.

By regulating the expression of numerous genes, cAMP could affect several intracellular pathways. These pathways appear to be effective over different time periods, suggesting that the regulation of persistent changes in synaptic strength or neuronal structure appears to be due to a cascade of mechanisms (Goelet et al., 1986; Montarolo et al., 1986; Byrne et al., 1993). For example, activation of protein kinase $A$ as a result of a brief sensitizing stimulus would not be sustained much beyond the period during which cAMP levels are elevated (Schwartz et al., 1983). A more prolonged sensitizing stimulus would result in modulation of membrane properties as a result of persistent activation of protein kinase A (Greenberg et al., 1987). The mechanism underlying this activation appears to be the selective degradation of regulatory subunits of the kinase (Hegde et al., 1993). This mechanism would be effective until the regulatory subunits were replenished by normal turnover (Greenberg et al., 1987; Schwartz and Greenberg, 1987). Longer term changes in synaptic plasticity could be mediated by more persistent changes in kinase activity induced by an as yet unknown mechanism (Sweatt and Kandel, 1989; Montarolo et al., 1992). Moreover, changes in neuronal strength lasting $24 \mathrm{hr}$ or longer could be mediated by changes in neuronal structure of the type described in this article.

Although the products of protein synthesis induced by cAMP appear to be important for long-term plasticity, critical steps in the regulatory pathway have not yet been identified (for review, see Byrne et al., 1993). One important protein that is synthesized soon after training is C/EBP, which is a trans-acting nuclear regulation factor (Umek et al., 1990; Alberini et al., 1994). It is not known, however, which genes are regulated by C/EBP. Another protein whose synthesis is altered is apCAM, a cell adhesion molecule. Synthesis of apCAM is reduced within the first hour after 5-HT application (Barzilai et al., 1989; Mayford et al., 1992). This is consistent with the rapid endocytosis of apC $\triangle \mathrm{M}$ from the plasma membrane, which may prepare the cell surface for structural remodeling (Bailey et al., 1992a). Moreover, synthesis of clathrin is increased soon after 5-HT treatment, presumably to support the endocytosis of apCAM (Kaang et al., 1993). At later time points, synthesis of cytoskeletal proteins such as actin and intermediate filaments are enhanced (Noel et al., 1993). These proteins presumably contribute to the neurite outgrowth induced by cAMP. The time course of these components of the response is consistent with the observation that structural remodeling develops gradually over the course of 24 hr (Bailey and Chen, 1989). Other proteins whose synthesis is increased several hours after 5-HT or cAMP treatment include BiP (Kuhl et al., 1992), calreticulin (Kennedy et al., 1992b), and calmodulin (Eskin et al., 1993; Zwartjes et al., 1991). Moreover, synthesis of mRNA encoding the protein phosphoglycerate kinase, an enzyme in the glycolytic pathway, is also increased (Fskin et al., 1993). Thus, while the requirement of protein synthesis for long-term modulation of synaptic strength has been clearly demonstrated, and proteins whose synthesis is regulated by procedures that mimic the training protocol have been identified, the full details of the mechanism remain to be elucidated.

\section{Contribution of structural remodeling to long-term synaptic}

\section{facilitation}

In Aplysia, sensory neurons are a critical site for the plasticity underlying sensitization (Castellucci and Kandel, 1976; Kupfer- mann et al., 1970; Kandel and Schwartz, 1982; Walters et al., 1983b; Scholz and Byrne, 1987). Modulation of sensory neurons by long-term sensitization or its in vitro analogues has been correlated with two classes of mechanisms, electrophysiological and structural. Most attention has focused on electrophysiological correlates because of their similarity to correlates of shortterm sensitization (Goelet et al., 1986). These include modulation of synaptic strength (Frost et al., 1985), membrane currents (Scholz and Byrne, 1987) and membrane excitability (Dale et al., 1987). Structural correlates of short-term sensitization have not yet been reported, although short-term synaptic depression does affect synaptic ultrastructure (Bailey and Chen, 1988c). Structural modifications of sensory neurons induced by longterm sensitization training include an increased number of varicosities and increased dendritic length (Bailey and Chen, 1988a) as well as modification of synaptic ultrastructure (Bailey and Chen, 1983). In the experiments reported here, analysis of changes in sensory neuron structure were limited to the pleural ganglion. At this location, these morphological changes could contribute to modification of the reflex by making new synapses with interneurons located in the pleural ganglion such as LPII7, RPI4, and RPl5 (Cleary and Byrne, 1993; Xu et al., 1994). These interneurons in turn make synaptic connections with motor neurons in the pedal ganglion. Additional experiments will be necessary to demonstrate that branches of sensory neurons in the pedal ganglion, where tail motor neurons are located, are also modified by cAMP injection.

An important issue is the functional relationship between electrophysiological and structural correlates of long-term sensitization. At this time, it is difficult to test independently these two classes of mechanisms. One indirect approach is to compare the effects of similar treatments on electrophysiological and structural correlates. Our results suggest that structural remodeling is sensitive to protein synthesis inhibitors during a period of time surrounding cAMP injection that lasts at least $8 \mathrm{hr}$. In cultured neurons, synaptic facilitation induced by $5-\mathrm{HT}$ was shown to be sensitive to anisomycin during a critical time period (Montarolo et al., 1986). This period was remarkably short; after a delay of just $0.5 \mathrm{hr}$, anisomycin was ineffective in blocking long-term facilitation, even when applied for a $22 \mathrm{hr}$ period after 5-HT application. This result suggested that a stable signal was induced during the training period that triggered a cascade of cellular events necessary to induce long-term facilitation. Our results were consistent with those of Montarolo et al. in that the period of sensitivity to anisomycin was limited, but differed in the duration of the critical period. This could be due to technical factors. For example, neurons that have been isolated into cell culture are regenerating, and may be in a different metabolic state than neurons in intact ganglia. Furthermore, 5-HT may result in more rapid stabilization of signal molecules than CAMP due to the activation of additional second messenger pathways (Baxter and Byrne, 1990; Braha et al., 1990; Sugita et al., 1992). Although the protein kinase $\mathrm{C}$-dependent pathway is not necessary for long-term facilitation (Schacher et al., 1988; Emptage and Carew, 1993), it may contribute to the rapid induction of a stable intracellular signal. On the other hand, our results are nearly identical to the time period during which binding of the nuclear protein C/EBP to DNA is required for long-term facilitation (Alberini et al., 1994). Nevertheless, we cannot rule out the possibility that long-term facilitation occurs under conditions in which structural remodeling is inhibited. If so, then the structural remodeling observed at $24 \mathrm{hr}$ could be a mechanism that 
contributes to later stages of memory retention, for example, at $48 \mathrm{hr}$ (Zhang et al., 1994). Nevertheless, it must be emphasized that the critical period for long-term facilitation in isolated ganglia is currently unknown, and may not be identical to that in cultured neurons.

Several forms of long-term learning in vertebrates as well as invertebrates are sensitive to inhibitors of protein synthesis (Flexner et al., 1963; Barondes, 1975; Squire, 1987). On the other hand, an example of long-term learning that is insensitive to inhibitors of protein synthesis has been reported recently (Wittstock et al., 1993). While relatively little work has been done on long-term sensitization itself, the results reported here are consistent with the effects of protein synthesis inhibitors on a behavioral model of long-term sensitization in a semi-intact preparation (Castellucci et al., 1989).

\section{References}

Alberini CM, Ghirardi M, Metz R, Kandel ER (1994) C/EBP is an immediate-early gene required for the consolidation of long-term facilitation in Aplysia. Cell 76:1-20.

Bacskai BJ, Hochner B, Mahaut-Smith M, Adams SR, Kaang BK, Kandel ER, Tsien RY (1993) Spatially resolved dynamics of cAMP and protein kinase A subunits in Aplysia sensory neurons. Science 260: 222-226.

Bailey CH, Chen M (1983) Morphological basis of long-term habituation and sensitization in Aplysia. Science 220:91-93.

Bailey CH, Chen M (1988a) Long-term memory in Aplysia modulates the total number of varicosities of single identified sensory neurons. Proc Natl Acad Sci USA 85:2373-2377.

Bailey CH, Chen M (1988b) Long-term sensitization in Aplysia increases the number of presynaptic contacts onto the identified gill motor neuron L7. Proc Natl Acad Sci USA 85:9356-9359.

Bailey $\mathrm{CH}$, Chen M (1988c) Morphological basis of short-term habituation in Aplysia. J Neurosci 8:2452-2459.

Bailey CH, Chen M (1989) Onset of structural changes at identified synapses and the acquisition of long-term sensitization in Aplysia. Soc Neurosci Abstr 15:1285.

Bailey CH, Kandel ER (1993) Structural changes accompanying memory storage. Annu Rev Physiol 55:397-426.

Bailey CH, Thompson EB, Castellucci VF, Kandel ER (1979) Ultrastructure of the synapses of sensory neurons that mediate the gillwithdrawal reflex. J Neurocytol 8:415-444.

Bailey CH, Chen M, Keller F, Kandel ER (1992a) Serotonin-mediated endocytosis of apCAM: an early step of learning-related synaptic growth in Aplysia. Science 256:645-649.

Bailey CH, Montarolo P, Chen M, Kandel ER, Schacher S (1992b) Inhibitors of protein and RNA synthesis block structural changes that accompany long-term heterosynaptic plasticity in Aplysia. Neuron 9:749-758.

Barondes SH (1975) Protein synthesis dependent and protein synthesis independent memory storage processes. In: Short-term memory (Deutsch D, Deutsch JA, eds), pp 379-390. New York: Academic.

Barzilai A, Kennedy TE, Sweatt JD, Kandel ER (1989) 5-H'T modulates protein synthesis and the expression of specific proteins during long-term facilitation in Aplysia sensory neurons. Neuron 2:15771586.

Baxter DA, Byrne JH (1990) Differential effects of cAMP and serotonin on membrane current, action-potential duration, and excitability in somata of pleural sensory neurons of Aplysia. J Neurophysiol 64: 978-990.

Bcrnicr L, Castellucei VF, Kandel ER, Schwartz JH (1982) Facilitatory transmitter causes a selective and prolonged increase in adenosine $3^{\prime}$ : 5 '-monophosphate in sensory neurons mediating the gill and siphon withdrawal reflex in Aplysia. J Neurosci 2:1682-1691.

Braha O, Dale N, Hochner B, Klein M, Abrams TW, Kandel ER (1990) Second messengers involved in the two processes of presynaptic facilitation that contribute to sensitization and dishabituation in Aplysia sensory neurons. Proc Natl Acad Sci USA 87:2040-2044.

Buonomano DV, Byrne JH (1990) Long-term synaptic changes produced by a cellular analog of classical conditioning in Aplysia. Science 249:420-423.
Byrne JH (1987) Cellular analysis of associative learning. Physiol Rev 67:329-439.

Byrne JH, Zwartjes R, Homayouni R, Critz SD, Eskin A (1993) Roles of second messenger pathways in neuronal plasticity and in learning and memory. Insights gained from Aplysia. Adv Second Messenger Phosphoprotein Res 27:47-108.

Castellucci VF, Kandel ER (1976) Presynaptic facilitation as a mechanism for behavioral sensitization in Aplysia. Science 194:11761178.

Castellucci VF, Frost WN, Goelet P, Montarolo PG, Schacher S, Morgan JA, Blumenfeld H, Kandel ER (1986) Cell and molecular analysis of long-term sensitization in Aplysia. J Physiol (Paris) 81:349-357.

Castellucci VF, Blumenfeld H, Goelet P, Kandel ER (1989) Inhibitor of protein synthesis blocks long-term behavioral sensitization in the isolated gill-withdrawal reflex of Aplysia. J Neurobiol 20:1-9.

Cleary LJ, Byrne JH (1993) Identification and characterization of a multifunction interneuron contributing to defensive arousal in Aplysia. J Neurophysiol 70:1767-1776.

Dale N, Kandel ER, Schacher S (1987) Serotonin produces long-term changes in the excitability of Aplysia sensory neurons in culture that depend on new protein synthesis. J Neurosci 7:2232-2238.

Dash PK, Hochner B, Kandel ER (1990) Injection of the cAMP-responsive element into the nucleus of Aplysia sensory neurons blocks long-term facilitation. Nature 345:718-721.

Eisenstadt M, Goldman JE, Kandel ER, Koike H, Koester J, Schwartz JH (1973) Intrasomatic injection of radioactive precursors for studying transmitter synthesis in identified neurons of Aplysia californica. Proc Natl Acad Sci USA 70:3371-3375.

Emptage NJ, Carew TJ (1993) Long-term synaptic facilitation in the absence of short-term facilitation in Aplysia neurons. Science 262: 253-256.

Eskin A, Nuñez-Regueiro M, Noel F, Homayouni R, Byrne JH, Zwartjes $R$ (1993) Identification of proteins whose mRNA levels are regulated by treatments producing long-term facilitation in Aplysia. Soc Neurosci Abstr 19:813.

Flexner JB, Flexner LB, Stellar E (1963) Memory in mice as affected hy intracerebral puromycin. Science 141:57-59.

Frost WN, Castellucci VF, Hawkins RD, Kandel ER (1985) Monosynaptic connections made by the sensory neurons of the gill- and siphon-withdrawal reflex in Aplysia participate in the storage of longterm memory for sensitization. Proc Natl Acad Sci USA 82:82668269.

Goelet P, Castellucci VF, Schacher S, Kandel ER (1986) The long and the short of long-term memory - a molecular framework. Nature 322: 419-422.

Greenberg SM, Bernier L, Schwartz JH (1987) Distribution of cAMP and cAMP-dependent protein kinases in Aplysia sensory neurons. J Neurosci 7:291-301.

Greenough WT, Bailey CH (1988) The anatomy of a memory: convergence of results across a diversity of tests. Trends Neurosci 11: 142-147.

Grollman AP (1967) Inhibitors of protein synthesis. J Biol Chem 242: 3226-3233.

Hegde AN, Goldberg AL, Schwartz JH (1993) Regulatory subunits of cAMP-dependent protein kinases are degraded after conjugation to ubiquitin: a molecular mechanism underlying long-term synaptic plasticity. Proc Natl Acad Sci USA 90:7436-7440.

Jacklet JW (1980) Protein synthesis requirement of the Aplysia circadian clock, tested by active and inactive derivatives of the inhibitor anisomycin. J Exp Biol 85:33-42.

Kaang BK, Kandel ER, Grant SG (1993) Activation of cAMP-responsive genes by stimuli that produce long-term facilitation in Aplysia sensory neurons. Neuron 10:427-435.

Kandel ER, Schwartz JH (1982) Molecular biology of learning: modulation of transmitter relcase. Science 218:433-443.

Kennedy TE, Hawkins RD, Kandel ER (1992a) Molecular interrelationships between short- and long-term memory. In: Neuropsychology of memory (Squire LR, Butters N eds), pp 557-574. New York: Guilford.

Kennedy TE, Kuhl D, Barzilai A, Sweatt JD, Kandel ER (1992b) Long-term sensitization training in Aplysia leads to an increase in calreticulin, a major presynaptic calcium-binding protein. Neuron 9:1013-1024.

Kuhl D, Kennedy TE, Barzilai A, Kandel ER (1992) Long-term sensitization training in Aplysia leads to an increase in the expression of 
BiP, the major protein chaperon of the ER. J Cell Biol 119:10691076.

Kupfermann I, Castellucci V, Pinsker H, Kandel E (1970) Neuronal correlates of habituation and dishabituation of the gill-withdrawal reflex in Aplysia. Science 167:1743-1745.

Mayford M, Barzilai A, Keller F, Schacher S, Kandel ER (1992) Modulation of an NCAM-related adhesion molecule with long-term synaptic plasticity in Aplysia. Science 256:638-644.

Montarolo PG, Goelet P, Castellucci VF, Morgan J, Kandel ER, Schacher S (1986) A critical period for macromolecular synthesis in longterm heterosynaptic facilitation in Aplysia. Science 234:1249-1254.

Montarolo PG, Ghirardi M, Kandel ER (1992) Contribution of persistent protein kinase A to serotonin-induced long-term facilitation of Aplysia sensory-motor synapses in culture. Soc Neurosci Abstr 18: 712.

Nazif FA, Byrne JH, Cleary LJ (1991) cAMP induces long-term morphological changes in sensory neurons of Aplysia. Brain Res 539: 324-327.

Noel F, Nuñez-Regueiro M, Cook R, Byrne JH, Eskin A (1993) Longterm changes in synthesis of intermediate filament protein, actin and other protcins in plcural sensory neurons of Aplysia. Mol Brain Res 19:203-210.

Schacher S, Castellucci VF, Kandel ER (1988) cAMP evokes longterm facilitation in Aplysia sensory neurons that requires new protein synthesis. Science 240:1667-1669.

Scholz KP, Byrne JH (1987) Long-term sensitization in Aplysia: biophysical correlates in tail sensory neurons. Science 235:685-687.

Scholz KP, Byrne JH (1988) Intracellular injection of cAMP induces a long-term reduction of neuronal $\mathrm{K}^{+}$currents. Science $240: 1664$ 1666.

Schwartz JH, Greenberg SM (1987) Molecular mechanisms for memory: second-messenger induced modifications of protein kinases in nerve cells. Annu Rev Neurosci 10:459-476.

Schwartz JH, Castellucci VF, Kandel ER (1971) Functioning of identificd ncurons and synapses in abdominal ganglion of Aplysia in the absence of protein synthesis. J Neurophysiol 34:939-953.
Schwartz JH, Bernier L, Castellucci VF, Palazzolo M, Saitoh T, Stapleton A, Kandel ER (1983) What molecular steps determine the time course of the memory for short-term sensitization in Aplysia? Cold Spring Harbor Symp Quant Biol 48:81 1819.

Squire LR (1987) Memory and brain. New York: Oxford UP.

Sugita S, Goldsmith JR, Baxter DA, Byrne JH (1992) Involvement of protein kinase $C$ in serotonin-induced spike broadening and synaptic facilitation in sensorimotor connections of Aplysia. J Neurophysiol 68:643-651.

Sweatt JD, Kandel ER (1989) Persistent and transcriptionally-dependent increase in protein phosphorylation in long-term facilitation of Aplysia sensory neurons. Nature 339:51-54.

Umek RM, Friedman AD, McKnight SL (1990) CCAAT-enhancer binding protein: a component of a differentiation switch. Science 251: 288-292.

Walters ET, Byrne JH, Carew TJ, Kandel ER (1983a) Mechanoafferent neurons innervating tail of Aplysia. I. Response properties and synaptic connections. J Neurophysiol 50:1522 1542 .

Walters ET, Byrne JH, Carew TJ, Kandel ER (1983b) Mechanoafferent neurons innervating tail of Aplysia. II. Modulation by sensitizing stimulation. J Neurophysiol 50:1543-1559.

Wittstock S, Kaatz H-H, Menzel R (1993) Inhibition of brain protein synthesis by cycloheximide does not affect formation of long-term memory in honeybees after olfactory conditioning. J Neurosci 13: $1379-1386$.

$\mathrm{Xu}$ YL, Cleary LJ, Byrne JH (1994) Identification of pleural neurons that inhibit tail sensory neurons and motor neurons in Aplysia: correlation with FMRFamide immunoreactivity. J Neurosci 14:35653577.

Zhang F, Goldsmith JR, Byrne JH (1994) Neural analogue of longterm sensitization training produces long-term ( 24 and $48 \mathrm{hr}$ ) facilitation of the sensory-to-motor neuron connection in Aplysia. J Neurophysiol 72:778-784.

Zwartjes R, Noel F, Byrne JH, Eskin A (1991) Calmodulin synthesis and mRNA level are regulated in Aplysia neurons by treatments producing long-term facilitation. Soc Neurosci Abstr 17:1590. 